\title{
ARANSEMEN LAGU “LELO LEDUNG” MENGGUNAKAN IDIOM-IDIOM PENTATONIK GAMELAN JAWA PADA PIANO SOLO
}

\section{ARRANGEMENT OF THE SONG "LELO LEDUNG" USING PENTATONIC IDIOMS JAVANESE GAMELAN ON SOLO PIANO}

\author{
Dody Ervina Yoga Abimanyu ${ }^{\text {; }}$ Dody Candra Harwanto ${ }^{2}$; \\ 1,2 Sekolah Tinggi Theoloia Abdiel, Ungaran, Indonesia \\ ${ }^{(*)} \bowtie$ (e-mail) dodyyoga12@gmail.com ${ }^{1}$, dcharwanto@gmail.com²,
}

\begin{abstract}
Abstrak
Perubahan sosial budaya suatu masyarakat yang disebabkan oleh teknologi dapat menghasilkan pola aktivitas kebudayaan baru seperti misalnya pada musik. Masyarakat mampu menikmati berbagai jenis musik melalui sebuah teknologi (televisi, radio, handphone) yang pada akhirnya memengaruhi selera musiknya yang cenderung meninggalkan musik-musik tradisional di daerahnya. Kondisi itu perlu diperhatikan dan dilakukan berbagai upaya-upaya, supaya kekhasan suatu daerah dapat tetap dilestarikan dengan nilai-nilai budaya yang ada didalamnya. Hal itu juga yang mendasari penulis dalam melakukan pengkajian musik dengan cara berinovasi melalui pembuatan aransemen musik. Tulisan ini bertujuan untuk membahas mengenai proses aransemen musik dengan menggunakan idiom-idiom pentatonik gamelan Jawa pada lagu Lelo Ledung yang dimainkan di piano. Hasil aransemen ini dapat digunakan sebagai alternatif pembelajaran musik untuk mengenalkan idiom-idiom musik tradisional gamelan dan lagu dolanan (Lelo Ledung) kepada generasi muda ataupun anak didik yang dimainkan pada alat musik modern yaitu piano.
\end{abstract}

Kata kunci: Aransemen, Lelo Ledung, Gamelan Jawa

\begin{abstract}
Socio-cultural changes of a society caused by technology can produce new patterns of cultural activity such as music. The society is able to enjoy various types of music through a technology (television, radio, handphone) which in turn affects the taste of music which tends to leave traditional music in the area. These conditions need to be considered and made various efforts, so that the uniqueness of an area can still be preserved with the cultural values that are in it. That also underlies the authors in conducting music studies by innovating through making music arrangements. This paper aims to discuss the process of arranging music by using Javanese gamelan pentatonic idioms on the song Lelo Ledung played on the piano. The results of this arrangement can be used as an alternative music learning to introduce the traditional musical idioms of gamelan and dolanan songs (Lelo Ledung) to the younger generation or students who are played on modern musical instruments, namely the piano.
\end{abstract}

Keywords: Arrangement, Lelo Ledung, Javanese Gamelan

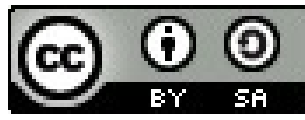

\section{Received: 3 Desember 2019 Revised: 8 Desember 2019 Available Online: 9 Desember 2019}




\section{Pendahuluan}

Kekayaan musik tradisional di Indonesia dalam perkembangannya mengalami kondisi yang memprihatinkan, dengan berkurangnya apresiasi dan sulitnya regenerasi, menyebabkan termarjinalnya kesenian oleh masyarakatnya sendiri-khususnya generasi muda. Sulitnya musik tradisional untuk berkembang juga tidak lepas dari semakin mengglobalnya masyarakat yang dengan mudah dapat menikmati berbagai musik di luar wilayahnya melalui teknologi seperti radio, televisi, handphone. Hal itu dapat dilihat dari berbagai media massa yang menyoroti apresiasi masyarakat dengan lebih cenderung menyukai kesenian dan budaya luar daripada budayanya sendiri (S. Handayani, 2008; T. Handayani, 2016). Selain itu beberapa penelitian lain juga menunjukkan adanya kondisi serupa yang disebabkan salah satunya oleh media massa, sehingga memengaruhi selera seni pada masyarakat (Ardini, 2016; Harwanto \& Sunarto, 2018; Rohidi, 2000).

Kondisi perubahan aktivitas kebudayaan baru pada suatu masyarakat patut untuk diperhatikan, supaya identitas daerah dapat tetap dilestarikan dan tidak hilang. Seperti misalnya salah satu musik tradisional yang sudah dikenal hingga taraf internasional yaitu musik gamelan, yang pada tahun 1889-1890 mendapat kesempatan untuk diikutsertakan dalam pameran internasional di Paris (Hartono, 2012). Namun pencapaian tersebut tidak diimbangi dengan apresiasi masyarakat-khususnya generasi muda-dewasa ini yang cenderung meninggalkan musik gamelan tersebut.

Selain musik-musik tradisional, karya sastra seperti misalnya lagu-lagu dolanan yang dulunya berkembang di suatu daerah juga sudah mulai jarang terdengar maupun dinyanyikan. Seperti misalnya lagu Lelo Ledung yang dikenal pada masyarakat Jawa ini sudah jarang dinyanyikan oleh anak-anak bahkan oleh orang tua pada saat menidurkan anaknya. Ini menunjukkan bahwa lagu-lagu dolanan keberadaanya makin terdesak oleh lagu-lagu populer, yang cenderung tidak sesuai dengan perkembangan kepribadian anak. Padahal lagu-lagu dolanan dapat menjadi sarana untuk pendidikan karakter anak, melalui makna lirik lagunya yang mendidik (Rosmiati, 2014).

Dalam lirik lagu Lelo Ledung mengandung beberapa fungsi yaitu sebagai regulatorisperintah/ nasihat-dan interaksi kedekatan orang tua kepada anaknya (Winarti, 2010). Pesan nasihat yang tergambar dari lagu tersebut adalah bagaimana seharusnya seseorang berperan sebagai orang tua, anak, dan anggota masyarakat (Setyaningsih, 2014). Pesan tersebut tentunya merupakan hasil pikiran masyarakat Jawa yang diwariskan turun-temurun melalui lagu dolanan tersebut.

Musik-musik tradisional dan lagu-lagu dolanan yang sudah dijelaskan oleh penulisdengan berbagai fungsinya-sudah sepatutnya diperhatikan, di dalam kondisi masyarakat yang dipengaruhi oleh dua budaya atau lebih, atau meminjam istilahnya (Spradley, 2007) yaitu "kebanjiran budaya" (culturally overwhelmed). Oleh karena itu sebagai upaya untuk mempertahankan keberadaan kebudayaan lokal, penulis berusaha mengaransemen lagu Lelo Ledung menggunakan idiom-idiom pentatonik gamelan Jawa yang dimainkan pada instrumen piano, agar generasi muda dapat tertarik dan menyukainya. Selain itu, pemilihan aransemen dengan menggunakan media instrumen piano dikarenakan instrumen ini mencakup seluruh unsur musik yaitu ritme, melodi, dan harmoni, serta menjadi salah satu alat musik modern yang sering dimainkan oleh generasi muda. 
Aransemen adalah penulisan ulang sebuah komposisi untuk suatu medium (alat musik, vokal, ansambel) yang berbeda dari komposisi aslinya. Aransemen membutuhkan keterampilan yang memadai agar sifat-sifat dasar dari karya yang diaransemen tidak berubah (Ammer, 2004). Oleh karena itu, terdapat hal yang diperhatikan oleh penulis pada saat melakukan proses aransemen yaitu penggunaan tangga nada. Dalam permainan piano yang identik dengan fungsi progresi akor sebagai dasar harmoninya, sedangkan dalam musik gamelan tidak mengenal sistem harmoni, maka perbedaan itu perlu diperhatikan dalam pembuatan aransemennya supaya karakteristik musik gamelan tetap dapat dimunculkan meskipun menggunakan alat musik piano. Proses aransemen dari R.M. Singgih Sanjaya digunakan oleh penulis sebagai pedoman dalam pembuatan aransemen ini.

\section{Gamelan Jawa}

Penjelasan singkat mengenai gamelan Jawa ini perlu diberikan, karena menjadi dasar dalam pembuatan aransemen yang dilakukan oleh penulis. Gamelan ialah perangkat alat musik tradisional yang juga dijumpai di berbagai wilayah Indonesia selain di Jawa, misalnya Sunda, Bali, dan lain-lain (KBBI, n.d.). Secara etimologis, asal usul kata gamelan yaitu gamel yang berarti pukul, dengan demikian gamelan dapat dimaknai seperangkat instrumen musik yang dimainkan dengan cara dipukul untuk menghasilkan bunyi musiknya.

Secara khusus Gamelan Jawa sering disebut dengan istilah karawitan-berasal dari bahasa Jawa yaitu rawit-yang memiliki makna rumit, berbelit-belit, namun juga berarti halus, cantik, berliku-liku dan enak (Kristanto, 2019). Instrumen gamelan secara fungsional musikal dapat di golongkan menjadi 3 kelompok: (a) kelompok alat musik balungan, yaitu alat musik yang berfungsi sebagai melodi utama lagu, yang terdiri dari saron barung, saron demung, saron penerus, slenthem (b) kelompok alat musik garap, yaitu alat musik yang berfungsi sebagai penghias lagu, yang terdiri dari rebab, kendhang, gender, gender penerus, penerus, siter, suling, gambang, sindhen, dan gerong, (c) kelompok alat musik struktural, yaitu alat musik yang berfungsi sebagai pembentuk ritme atau ketukan, yang terdiri dari kethuk, kempyang, engkuk, kemong, kenong, kempul, gong, kecer, kemanak, keplok-alok, dan kendhang (Supanggah, 2009).

Instrumen gamelan terdiri atas dua laras yaitu pelog dan slendro. Laras pelog memiliki tujuh nada dasar yakni nada ji (siji=1), ro (loro=2), lu (telu=3), pat (papat=4), ma (lima=5), nem (enem=6), dan pi (pitu=7. Perbedaan frekuensi antarnada tidak sama (mirip dengan nada diatonis). Laras slendro memiliki 5 nada dasar, yakni nada ji (1), ro (2), lu (3), ma (5), dan nem (6). Pada laras slendro tidak terdapat nada pat (4). Perbedaan frekuensi antarnada pada gamelan adalah sama (Kridalaksana, Rahyono, Puspitorini, Widodo, \& Darmoko, 2001).

\section{Aransemen Musik}

Aransemen adalah gubahan lagu untuk orkes atau kelompok paduan musik baik vokal maupun instrumental (Kridalaksana et al., 2001). Aransemen adalah penulisan ulang suatu komposisi (intrumental, vokal ataupun ansambel) yang berbeda dengan komposisi aslinya, dengan menggunakan ketrampilan dan kreativitas. Orang yang melakukan aransemen dikenal dengan sebutan 'arranger'. Mengaransemen membutuhkan suatu kemampuan untuk mengolah melodi, ritme, harmoni dari komposisi aslinya, sehingga dapat memunculkan gaya baru tanpa menghilangkan ciri khas dari komposisi aslinya (Ammer, 2004).

Penulis menggunakan proses dalam melakukan aransemen dari R.M. Singgih Sanjaya yang diuraikannya dalam lima langkah pembuatan aransemen yaitu (1) konsep aransemen, 
(2) aransemen awal, (3) menciptakan ide-ide baru, (4) aransemen lanjut, (5) evaluasi dan revisi (Sanjaya, 2013). Tahapan aransemen tersebut dijadikan dasar oleh penulis dalam melakukan proses aransemen hingga pada akhirnya dapat menghasilkan sebuah karya aransemen yang baru.

Di dalam konsep mengaransemen, ada lima hal yang perlu diperhatikan oleh seorang arranger. Pertama, menentukan tujuan dalam membuat aransemen. Tujuan ini perlu dirancang sebagai tahap awal arranger sebelum masuk ke dalam hal teknis, sehingga konsep musik yang akan tuangkan ke dalam unsur-unsur musiknya menjadi lebih jelas dan terarah. Kedua, penentuan instrumen musik yang digunakan untuk membuat aransemen, dengan memerhatikan apakah instrumen yang dipilih itu sesuai pada tujuan/ fungsi lagu yang diaransemen. Ketiga, menentukan tingkat keterampilan yang dibutuhkan untuk memainkan karya aransemen yang dibuat. Keempat, memahami lirik lagu pada karya yang akan diaransemen. Hal ini dilakukan supaya hasil karya aransemen memiliki karakteristik yang sesuai dengan makna dari lagu aslinya serta dijadikan dasar dalam berimajinasi dan memperkaya fantasi untuk membuat aransemennya. Dan kelima, mendeskripsikan target pencapaian dalam pembuatan aransemen, atau dapat dikatakan sebagai sketsa (Sanjaya, 2013).

Dalam proses aransemen awal, dapat dilakukan dengan menulis notasi lagu dan menentukan nada dasar, mencari akor, menentukan pola iringan (rhythm pattern), menyusun atau menciptakan intro-interlude-koda dan menentukan ekspresi lagu. Tahap ini memerlukan penulisan yang rinci untuk menghindari ide-ide musikal yang ada dalam benak arranger tidak hilang (Sanjaya, 2013).

Dalam proses memodifikasi dan menciptakan ide-ide baru, garapan aransemen akan menarik jika di dalamnya terdapat ide-ide musikal yang baru, unik maupun garapan yang dimodifikasi dengan materi yang sudah ada. Ada dasar-dasar estetika dari Jelantik yang perlu diperhatikan dalam menyusun sebuah aransemen. Filosofi keindahan tersebut adalah:

a. Unity, bahwa sebuah karya seni yang tergolong estetis jika karya tersebut bersifat menyatu atau secara keseluruhan merupakan satu kesatuan.

b. Unique, sebuah karya seni akan menarik jika di dalamnya terdapat unsur yang 'unik', sehingga mempunyai ciri khas yang kuat dan berbeda dengan karya-karya pada umumnya.

c. Complecivity, atau 'kerumitan' adalah simbol dari 'karya besar', hampir dapat dipastikan bahwa sebuah karya besar di dalamya terdapat kerummitan-kerumitan.

d. Reprecentative, bahwa sebuah karya seni yang mempunyai nilai estetika yang tinggi adalah merepresentasikan atau mewakili seniman penciptanya secara pribadi.

Perlu dipahami bahwa memodifikasi bisa dilakukan dengan memodifikasi motif, mencari alternatif akor yang berbeda, variasi-variasi melodi, ritme harmoni atau akor, perancangan filler atau isian.

Selanjutnya pada proses aransemen lanjut adalah upaya menyatukan dari langkah pertama sampai ketiga. Arranger harus memiliki imajinasi untuk mempersatukan satu demi satu materi-materi yang sudah dirancang dan dapat menuangkannya atau menuliskannya di dalam sebuah partitur. Bisa melalui software penulisan notasi musik yaitu: Sibelius, Finale, Encore, dll. Selain itu juga dapat merekam hasil penggabungan materi-materi yang sudah ada. 
Sedangkan pada tahapan akhir yaitu proses evaluasi dan revisi yang di dalamnya melakukan kegiatan mendengarkan hasil aransemen secara seksama, mengevaluasi dan merevisi.

\section{Aransemen Lagu "Lelo Ledung" Menggunakan Idiom-Idiom Pentatonik Gamelan Jawa Pada Piano Solo}

Aransemen lagu Lelo Ledung yang dilakukan penulis diawali dengan menentukan konsep aransemen. Tujuan dalam pembuatan aransemen ini adalah untuk mengenalkan kembali lagu daerah ke dalam bentuk yang baru menggunakan piano dan dapat menjadi alternatif pembelajaran musik tradisional di sekolah dalam kegiatan apresiasi dan kreasi dengan menggunakan alat musik modern seperti piano/ keyboard. Instrumen yang dipilih adalah piano, karena alat musik ini memiliki range nada yang luas dan menjadi salah satu alat musik modern, dengan pertimbangan bahwa penggunaan alat musik modern tersebut dapat menarik minat masyarakat khususnya generasi muda untuk memainkan atau mendengarkan. Tingkat keterampilan pada aransemen ini ditujukan untuk pianis yang mempunyai tingkat kemahiran menengah ke atas. Dalam proses pembuatan aransemen ini, penulis juga mempertimbangkan makna dari lirik lagu Lelo Ledung sebagai bahan ekspresi dan imajinasi yang dituangkan ke dalam unsur-unsur musiknya, sehingga terjadi kesesuaian kesan antara makna lagu dengan karya yang dimainkan.

Tahap aransemen awal dilakukan oleh penulis dengan menuliskan melodi lagu dan menentukan pembukaan lagu (introduction), peralihan lagu/ penghias lagu (bridge) dan penutup lagu (coda). Pada pembukaan lagu, melodi yang disusun dengan mengimitasi pola permainan gender dan memasukan dinamika pianisimo dengan tujuan untuk membuat suasana teduh dan mendayu-dayu. Penulis menyajikan potongan partitur dari lagu pembuka yang dapat dilihat pada gambar 1.

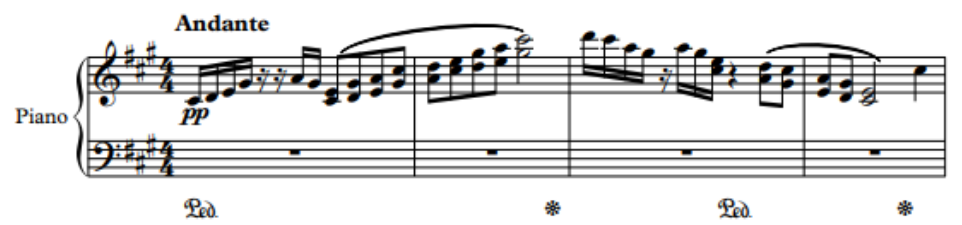

Gambar 1. Ritme gender pada pembuka lagu aransemen

(Abimanyu, 2019)

Pada bagian penghias lagu atau musik tengah, pembuatan melodi diatur dengan mengimitasi pola permainan gambang yang ditandai dengan not seperenambelas yang menjadi karakteristik dari pola permainan gambang. Berikut penulis menyajikan potongan partitur penghias lagu yang dapat dilihat pada gambar 2 .

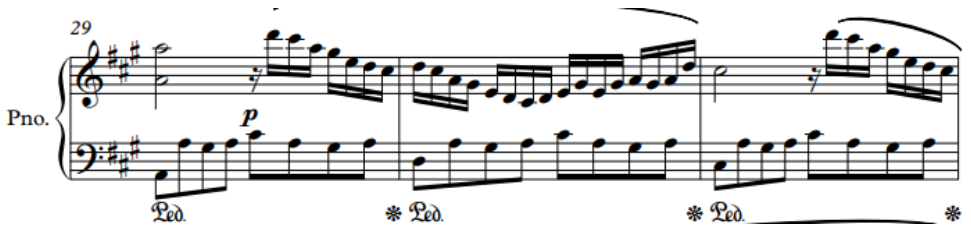

Gambar 2. Ritme gambang pada penghias lagu aransemen

(Abimanyu, 2019) 
Sedangkan pada bagian penutup lagu, melodi diatur dengan cara mengimitasi pola permainan bonang dalam irama sampak atau srepeg dan memasukan perubahan kecepatan seperti adagio-allegreto-allegro, serta menambah perubahan dinamika dari mezzopianopiano-mezzoforte-forte. Hal ini dilakukan supaya aransemen yang disusun memberikan kesan "klimaks" atau sampai pada puncaknya. Berikut ini penulis menyajikan potongan partitur penutup lagu yang dapat dilihat pada gambar 3.

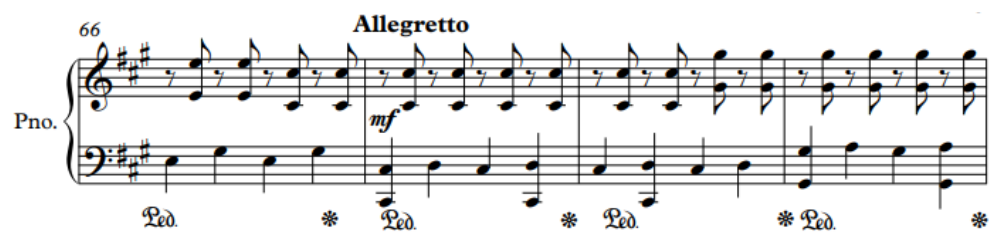

Gambar 3. Ritme sampak atau srepeg pada penutup lagu aransemen (Abimanyu, 2019)

Pengaturan aransemen pada bagian awal, tengah, dan akhir sudah selesai dilakukan (dan tidak terlepas dari proses revisi dari penulis), lalu dilanjutkan dengan menentukan iringan lagu "Lelo Ledung", melalui penggunaan imitasi pola permainan saron dan gong, agar pergantian akor atau bassnya tetap dapat dirasakan. Berikut ini penulis menyajikan potongan bentuk iringan yang dapat dilihat pada gambar 4 .

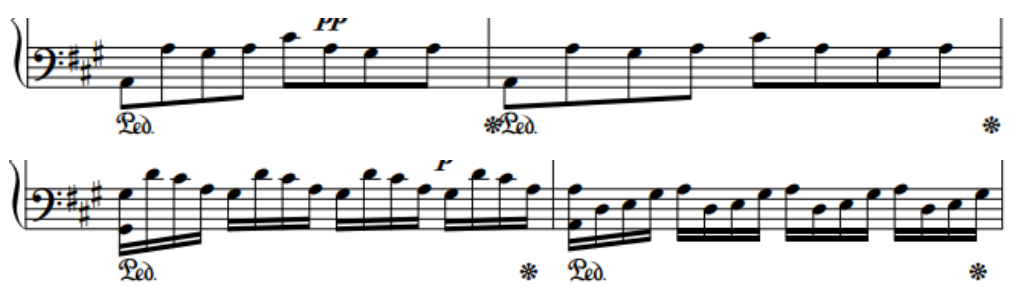

Gambar 4. Ritme iringan pada aransemen

(Abimanyu, 2019)

Selanjutnya, penulis melakukan modifikasi dan menemukan ide-ide baru, dengan membuat tanda ekspresi pada lagu, teknik-teknik aransemen yang dapat menambah kesan kemegahan lagu, dan juga memperhatikan peralihan tempo serta melakukan variasi irama dan perancangan isian.

Setelah penyusunan aransemen awal sudah selesai, dilanjutkan dengan proses aransemen lanjut. Pada proses aransemen lanjut ini, dilakukan dengan cara menggabungkan bagian-bagian lagu yang sudah disusun menjadi satu kesatuan lagu (aransemen) yang utuh melalui penulisan notasi di software sibelius dan diperdengarkan dengan seksama terhadap hasil aransemen secara utuh.

Pada tahap akhir proses aransemen ini adalah melakukan evaluasi dan revisi kembali hingga pada akhirnya diperoleh hasil yang final dengan berbagai pertimbangan-pertimbangan seperti melihat kembali konsep aransemen, ekspresi musikal aransemen yang menggunakan idiom-idiom pentatonik gamelan Jawa, kesesuaian makna lagu dengan hasil aransemen, dan dengar pendapat dari Royke Bobby Koapaha M.Sn yang berprofesi sebagai staf pengajar di Prodi Penciptaan Musik ISI Yogyakarta dan Mario Abraham Warouw S.Mus yang berprofesi sebagai komposer orkestra serta pengajar ansambel gesek di Universitas Kristen Satya Wacana Salatiga. 
Hasil aransemen ini terdiri dari 85 birama yang menyajikan konsep aransemen dengan mengimitasi pola permainan dari instrumen gamelan Jawa. Bentuk lagu masih sama seperti lagu aslinya yaitu A-A'-B-A'. Penulis menggunakan nada dasar $A$ mayor, dikarenakan nada dasar tersebut memiliki kemiripan bunyi dengan dibeberapa pertunjukan gamelan Jawa dan digunakan dalam pemesanan pembuatan gamelan (Yulianto \& Hananto, 2009).

Peneliti juga ingin membuat suasana lagu seperti lagu penghantar tidur, dengan mengedepankan suasana yang tenang, lembut dan penuh dinamika melalui tempo yang lambat. Tempo menjadi unsur yang penting dalam memengaruhi ekspresi emosi pendengar dan menstimulasi perubahan fisik pendengarnya, sehingga tempo menjadi unsur yang perlu diperhatikan dalam sebuah karya musik untuk menghasilkan efek-efek fisik tertentu (Djohan, 2005). Berikut ini penulis menjelaskan hasil aransemen secara utuh yang sudah dibuat dari bagian awal hingga akhir.

Pada birama 1-12 penulis membuat suasana pembuka lagu dengan mengimitasi pola permainan gender. Selain suasana dari iringan gender yang teduh dan lembut, serta berfungsi sebagai penghias lagu di dalam gamelan, juga terdapat keunikan pada iringan gender yang dapat dikatakan tidak memiliki tanda sukat yang jelas. Pola permainan gender yang diimitasi yaitu pola permainan lampah II dan lampah IV dengan mengombinasikan not seperdelapanan dan seperenambelasan. Dan pada birama ke 12 (sebagai bagian akhir dari pembuka lagu) diakhiri dengan rit yang bertujuan untuk mengimitasi suara gong. Berikut ini penulis menyajikan gambar partitur hasil aransemen bagian pembuka, yang dapat dilihat pada gambar 5.

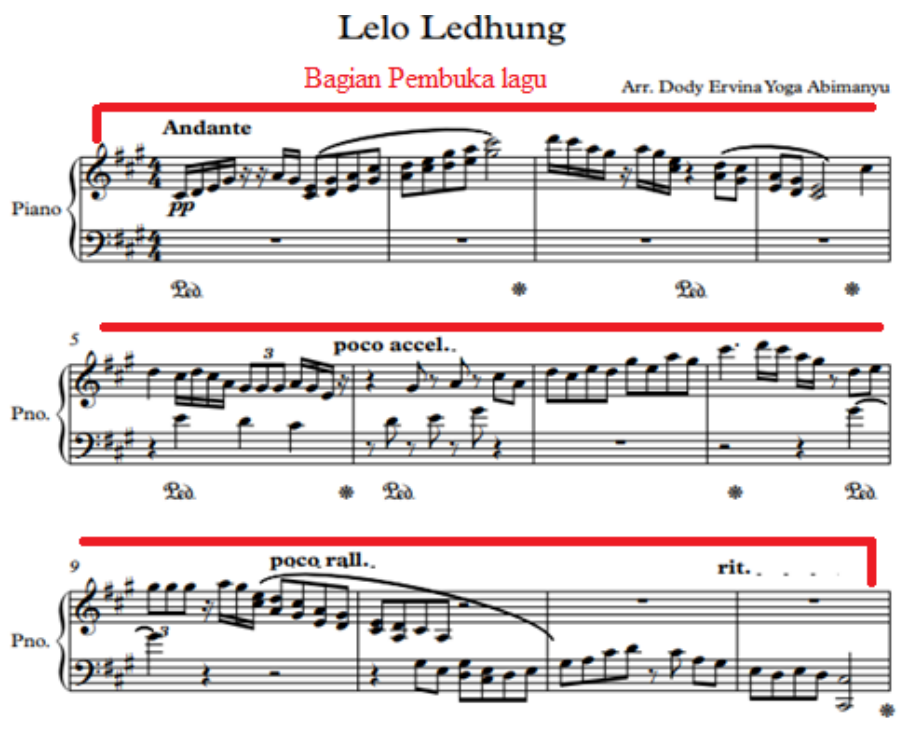

Gambar 5. Hasil aransemen bagian pembuka

(Abimanyu, 2019)

Birama 13-21 di ketukan pertama merupakan bagian A lagu "Lelo Ledung". Penulis membuat melodi utama menggunakan oktaf, karena ingin mengimitasi pola permainan demung dan saron penerus yang berfungsi sebagai melodi utama dalam permainan musik gamelan Jawa. Penulis juga menambahkan teknik arpeggio, supaya memiliki kesan seperti musik gamelan yang dimainkan oleh banyak orang dan terkadang tidak sama pola ketukannya. Pada bagian iringan, penulis mengimitasi gong ageng dan saron penerus (tabuhan ngracik). Hal itu karena gong ageng berfungsi sebagai tanda pergantian nada sehingga untuk iringan akan jelas jika nadanya berubah, dan memilih tabuhan ngracik, karena 
memang iringannya memainkan not seperdelapanan dan terpola, selain itu juga penulis memasukan teknik memecah akor pada pola iringan. Penulis sengaja membuat pola iringannya sama, agar mudah didengar atau dinikmati (easy listening). Berikut ini penulis menyajikan gambar partitur hasil aransemen bagian A, yang dapat dilihat pada gambar 6 .

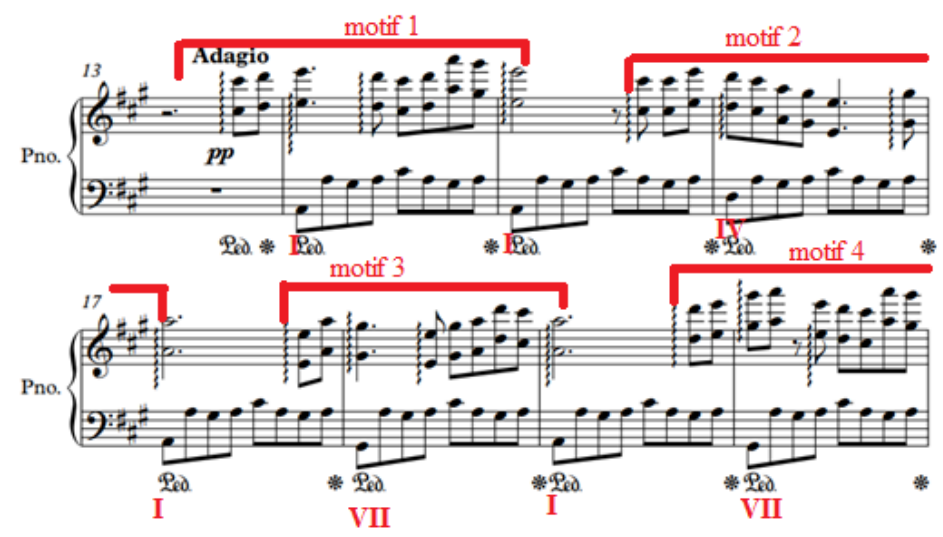

Gambar 6. Hasil aransemen bagian A

(Abimanyu, 2019)

Birama 21-29 ketukan pertama adalah bagian A'. Penulis mempertahankan melodi utama dengan mengimitasi pola permainan demung dan saron (nibani), supaya melodi utama terdengar di double, ini dilakukan agar melodi terdengar kuat. Pada bagian iringan masih sama dengan iringan di bagian A yang mengimitasi gong ageng, dan saron penerus (tabuhan ngracik). Pembuatan pola iringan yang sama ini supaya iringan tidak terlalu menonjol. Berikut penulis menyajikan gambar partitur hasil aransemen bagian $A^{\prime}$, yang dapat dilihat pada gambar 7.

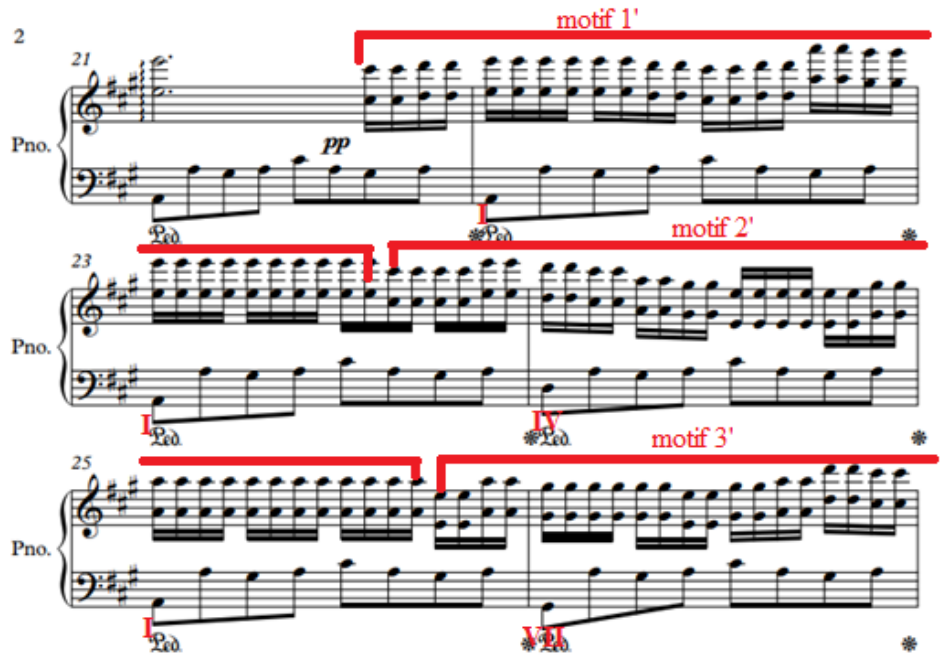




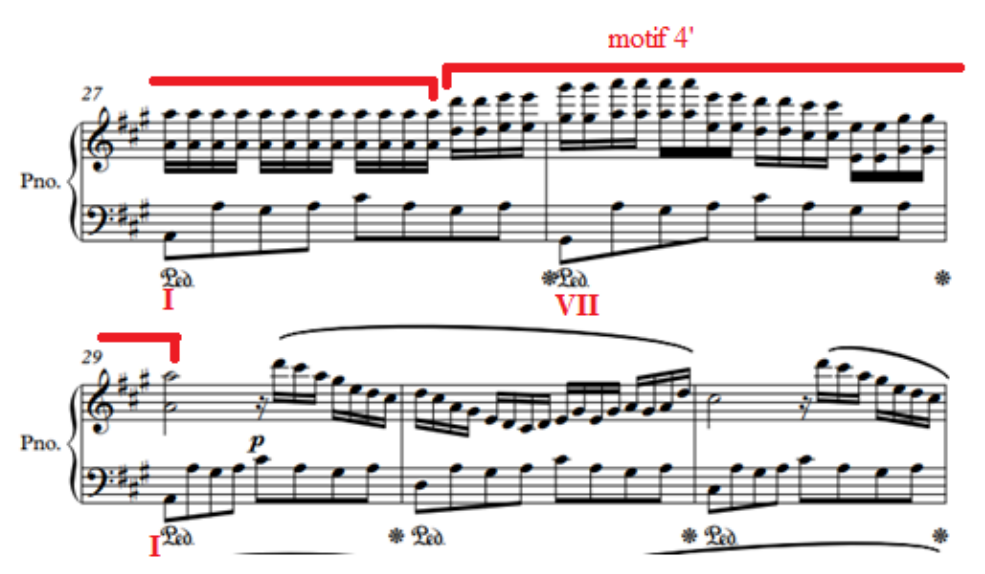

Gambar 7. Hasil aransemen $A^{\prime}$

(Abimanyu, 2019)

Birama 29 ketukan ketiga hingga birama 41 adalah bagian penghias lagu. Penulis ingin memberi jeda sebelum masuk ke bagian B. Dalam jeda tersebut penulis mengimitasi pola permainan gambang yang menggunakan irama dadi, di mana pengolahan melodi mengikuti jatuhnya bunyi pada gong atau kempul-dalam musik Barat yaitu pada bassnya-di birama 29-37 ketukan pertama. Pada birama 37 ketukan ketiga hingga 40, penulis mengimitasi pola permainan saron tabuhan ngapinjal dan tabuhan ngracik atau biasa dikenal dengan tabuhan imbalan yaitu saron demung dan saron penerus saling bersaut-sautan.

Pada birama 41 diakhiri dengan gong ageng yang disertai rit dan sebagai tanda untuk masuk pada bagian $B$ lagu. Untuk pola iringannya masih sama yaitu penulis mengimitasi gong ageng, dan saron penerus (tabuhan ngracik). Ini dilakukan agar aransemen terlihat tidak membosankan karena ada penghias lagunya. Selain itu juga penulis ingin memperlihatkan kecepatan pola permainan dari gambang. Berikut ini penulis menyajikan gambar partitur hasil aransemen bagian penghias lagu, yang dapat dilihat pada gambar 8 .

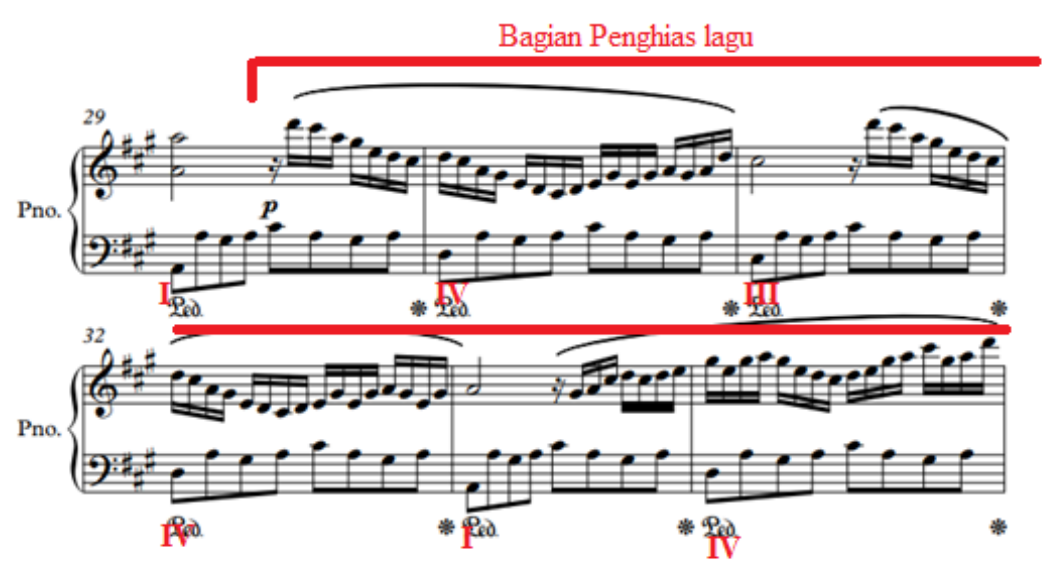



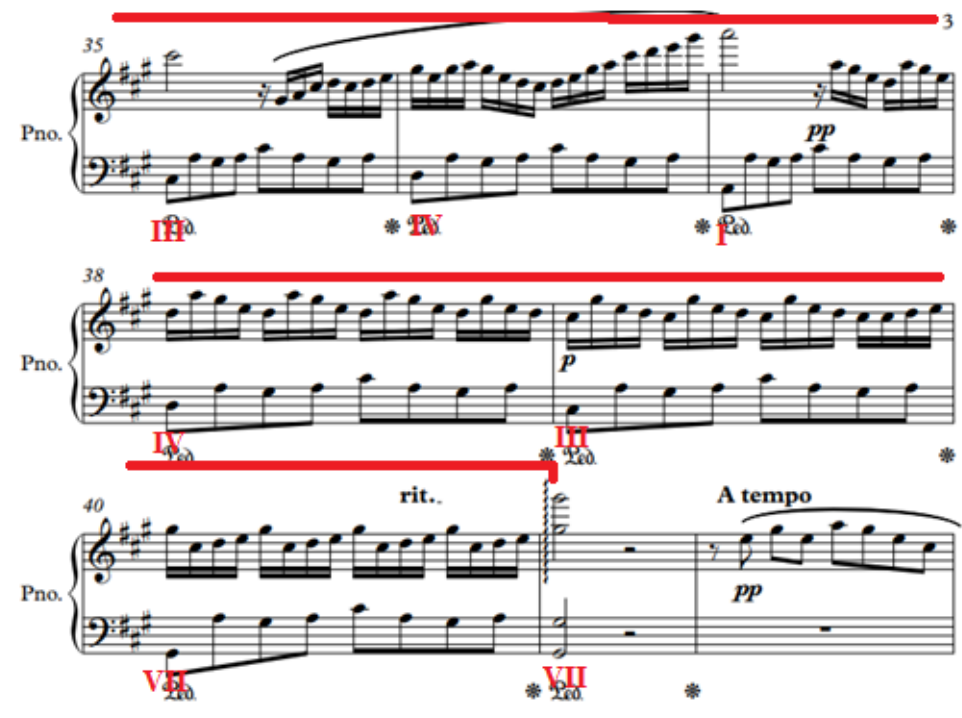

Gambar 8. Hasil aransemen bagian penghias lagu

(Abimanyu, 2019)

Bagian B terdiri dari birama 42-49 ketukan kedua. Penulis mempertahankan melodi utama, hanya saja pola iringannya mengimitasi permainan saron demung, saron penerus, dan gong ageng. Mengimitasi tabuhan demung dan saron tabuhan ngapinjal dan tabuhan ngracik atau biasa dikenal dengan tabuhan imbalan yaitu saron demung dan saron penerus saling bersaut-sautan, yang diawali oleh bunyi gong ageng sebagai tanda beralihnya nada atau sebagai bassnya. Pola iringan ini biasanya dikenal dengan imbal-permainan bersahutsahutan antara bonang dan saron dalam karawitan Jawa dan karawitan Sunda (Banoe, 2003). Ini dilakukan agar terlihat berbeda dengan pola iringan yang sebelumnya dan agar aransemen mendapatkan klimaksnya. Berikut ini penulis menyajikan gambar partitur hasil aransemen bagian B, yang dapat dilihat pada gambar 9 .

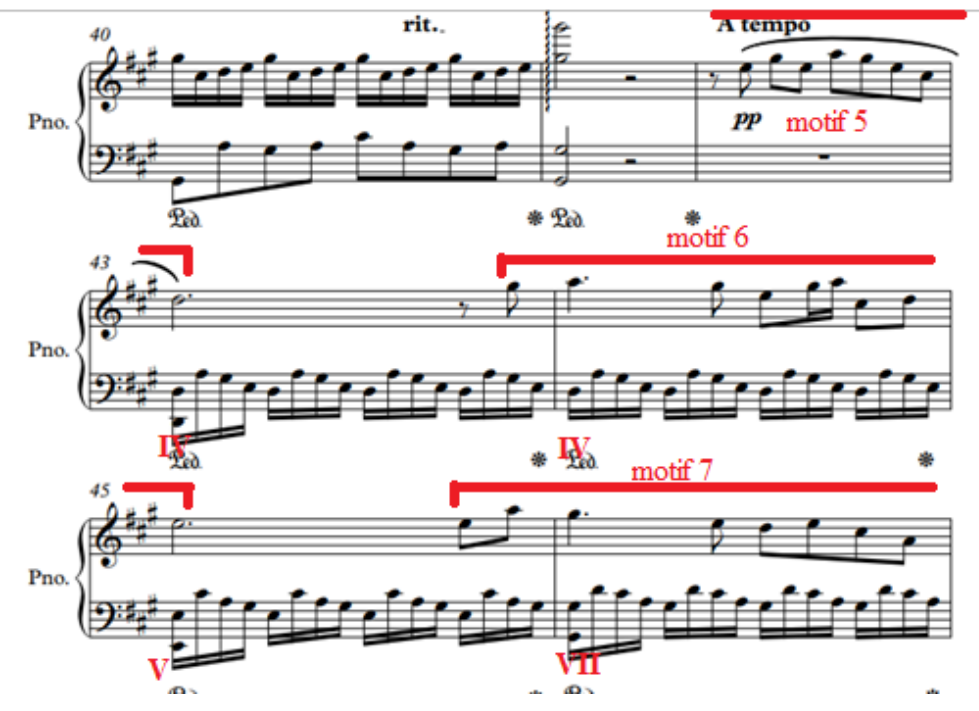



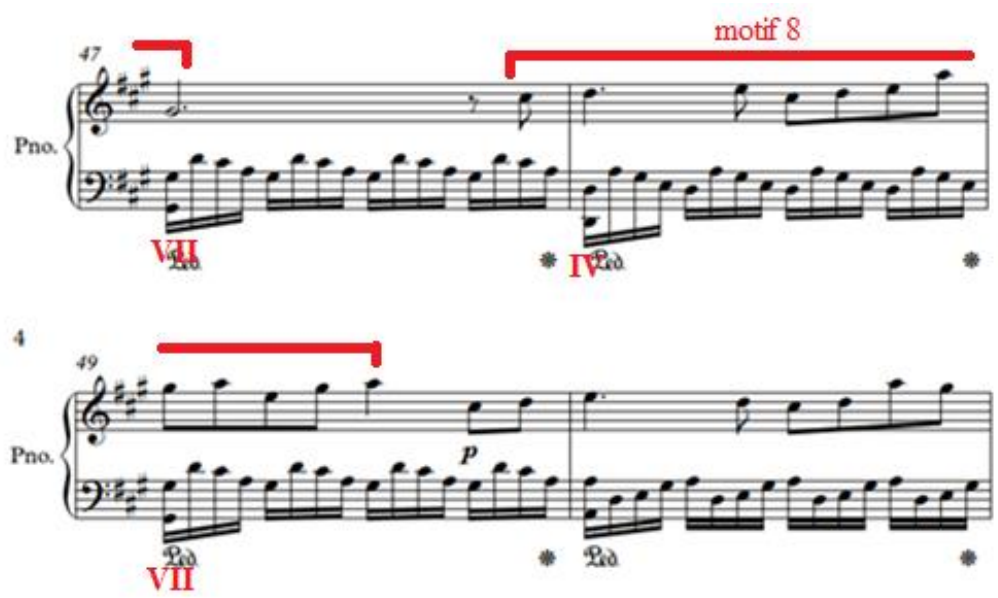

Gambar 9. Analisis hasil aransemen bagian $B$

(Abimanyu, 2019)

Pada bagian A' terdiri dari birama 49 ketukan keempat hingga birama 57 ketukan pertama. Peneliti mempertahankan melodi utama, hanya saja pola iringannya mengimitasi permainan saron demung, saron penerus dan gong ageng. Mengimitasi tabuhan demung dan saron tabuhan ngapinjal dan tabuhan ngracik atau biasa dikenal dengan tabuhan imbalan yaitu saron demung dan saron penerus saling bersaut-sautan, yang diawali oleh bunyi gong ageng sebagai tanda beralihnya nada atau sebagai bassnya. Hal ini dilakukan agar terlihat berbeda dengan pola iringan bagian $A$ dan agar aransemen mendapatkan klimaksnya. Berikut peneliti menyajikan gambar partitur hasil aransemen bagian $A^{\prime}$, yang dapat dilihat pada gambar 10.
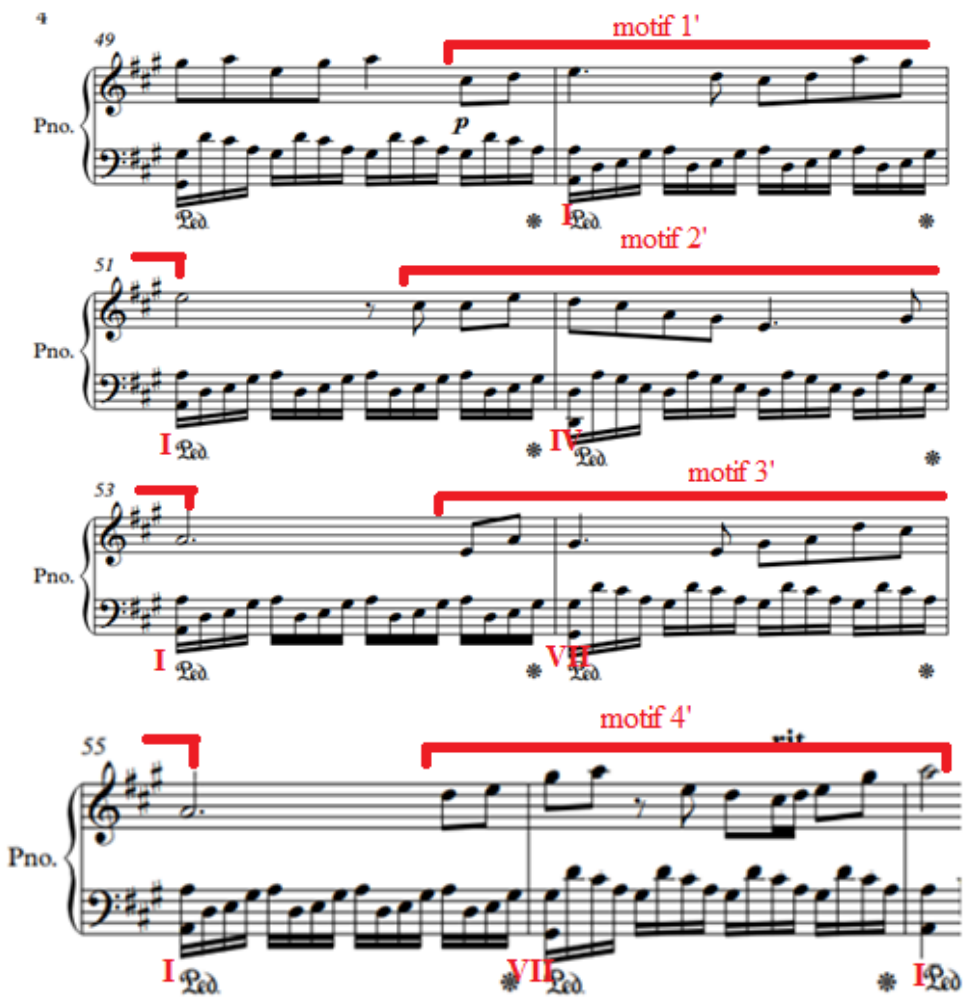

Gambar 10. Hasil aransemen bagian $A^{\prime}$

(Abimanyu, 2019) 
Pada birama 57 ketukan ketiga hingga birama 85, penulis membuat suasana penutup dari lagu diakhiri dengan bentuk sampak. Sampak adalah komposisi gending Jawa yang banyak mempergunakan kenong dan kempul secara padat dalam tempo yang cepat. Umumnya dikenal dengan srepegan-gending Jawa yang biasanya dimainkan dengan kecepatan yang mendesak (Banoe, 2003). Penulis mengolah melodi dengan mengimitasi bonang (tabuhan bonang gembyang) dan kenong (tabuhan kenong tuturan), sedangkan pada iringannya mengimitasi gong ageng, kempul dan demung. Melodi dan iringan diulang terusmenerus hingga terdapat perubahan tempo yang semakin cepat, dan diakhiri dengan rit. Pada bagian ini penulis ingin supaya aransemen terlihat semakin mencapai puncak lagu dan sebagai tanda akhir dari aransemen. Berikut ini penulis menyajikan gambar partitur hasil aransemen bagian penutup lagu, yang dapat dilihat pada gambar 11 .
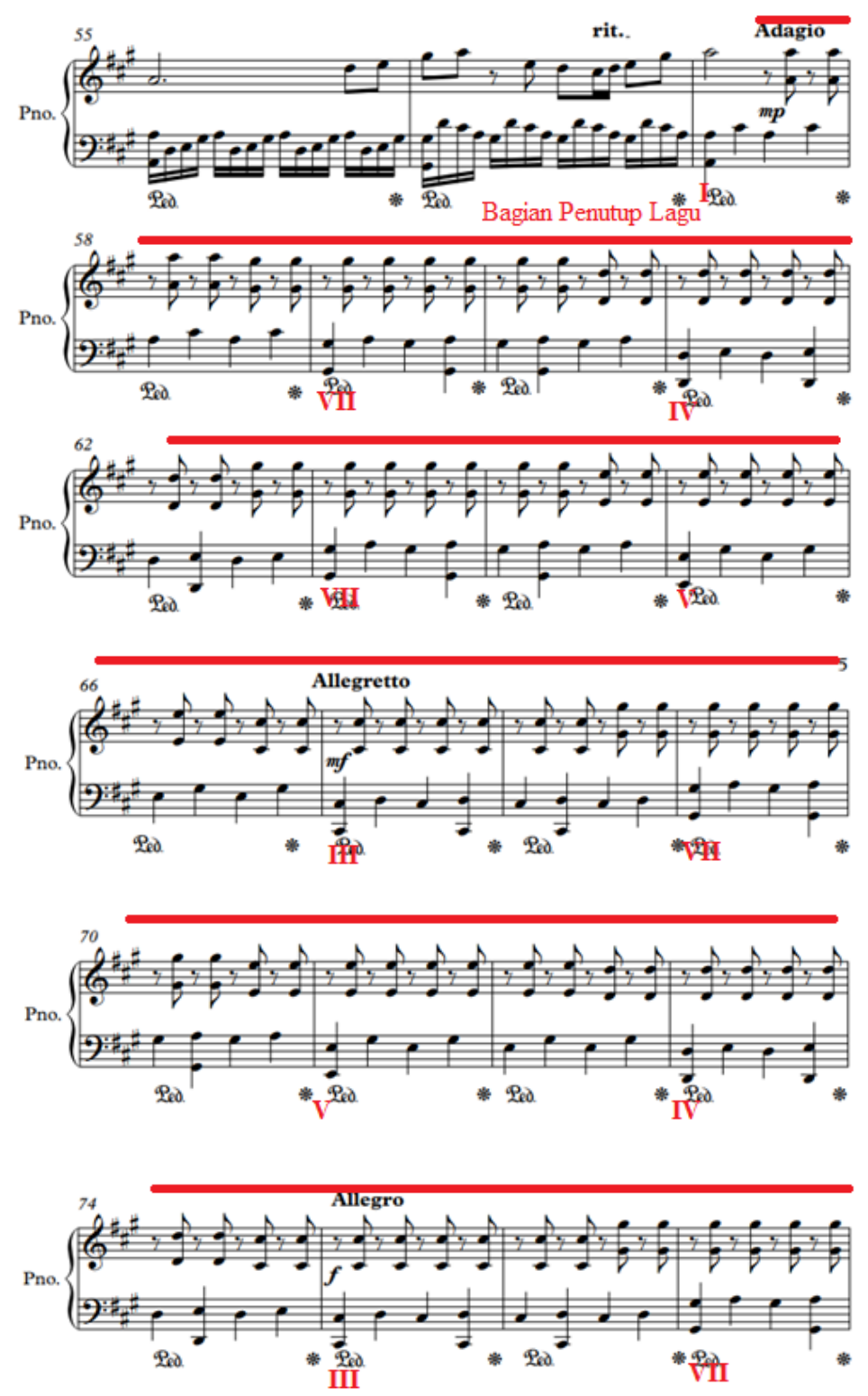

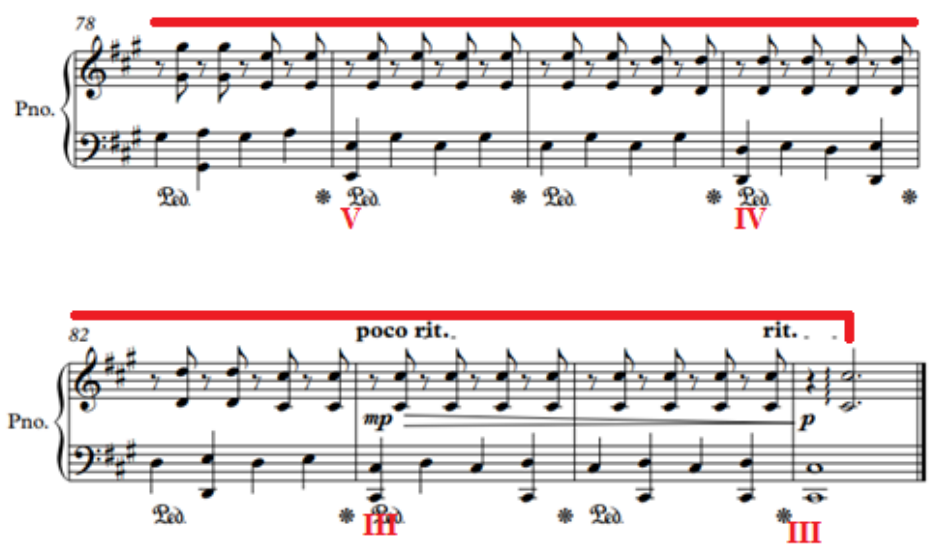

Gambar 11. Hasil aransemen bagian penutup lagu (Abimanyu, 2019)

\section{Kesimpulan}

Hasil karya aransemen yang dilakukan oleh penulis pada akhirnya dapat menghasilkan karya baru sebagai alternatif dalam memainkan idiom-idiom musik gamelan dan lagu dolanan Lelo Ledung melalui instrumen piano. Adanya bentuk karya baru yang 'modern' ini, diharapkan dapat menjadi media ekspresi dan apresiasi bagi generasi muda terhadap budayanya sendiri. Selain itu, proses aransemen dengan cara mengimitasi beberapa pola permainan pada gamelan Jawa-seperti saron, demung, gong, kempul, dan gambang-yang diterapkan pada piano, dapat menjadi pemantik untuk berkreativitas melalui media musik. Dengan demikian, nilai-nilai budaya yang tercermin dalam musik-musik tradisional dan lagulagu dolanan maupun daerah dapat tetap dilestarikan melalui bentuk-bentuk baru.

\section{References}

Ammer, C. (2004). The Facts On File Dictionary of Music. New York: Facts On File, Inc.

Ardini, I. W. (2016). Produksi, Distribusi, dan Konsumsi dalam Industrialisasi Musik Pop Bali. Jurnal Seni Budaya, 31(1), 54-63.

Banoe, P. (2003). Kamus Musik. Yogyakarta: Kanisius.

Djohan. (2005). Psikologi Musik. Yogyakarta: Buku Baik.

Handayani, S. (2008). Anak Muda Ogah Melirik Seni Tradisional Anak Muda Ogah Melirik Seni Tradisional. Kompas.Com, pp. 1-2. Retrieved from https://nasional.kompas.com/read/2008/09/14/02422737/anak.muda.ogah.melirik.se ni.tradisional

Handayani, T. (2016). Wayang Kulit Dilupakan di Negeri Sendiri. Tribunnews.Com. Retrieved from https://www.tribunnews.com/tribunners/2016/01/13/wayang-kulit-dilupakandi-negeri-sendiri

Hartono. (2012). Perkembangan Estetika Musikal Seni Karawitan Jawa dan Pengaruhnya Terhadap Masyarakat Pendukungnya. Jurnal Online Universitas Malang Fakultas Media Seni Dan Desain, 1(1), 1-25. Retrieved from http://jurnalonline.um.ac.id/article/do/detail-article/1/12/376 
Harwanto, D. C., \& Sunarto. (2018). Bentuk dan Struktur Kesenian Kentrung di Jepara. Jurnal Resital: Journal of Performing Arts, 19(1), 35-45.

KBBI. (n.d.). Gamelan. Retrieved June 17, 2019, from https://kbbi.web.id/gamelan

Kridalaksana, H., Rahyono, F. X., Puspitorini, D., Widodo, S., \& Darmoko. (2001). Wirwara: Pengantar Bahasa dan Kebudayaan Jawa. Jakarta: PT Gramedia Pustaka Utama.

Kristanto, A. (2019). Kontekstualisasi Gamelan Jawa di Gereja Baptis Indonesia (GBI) Ngembak. Tonika: Jurnal Penelitian Dan Pengkajian Seni, 2(1), 19-31. Retrieved from http://journal.stt-abdiel.ac.id/tonika/article/view/40

Rohidi, T. R. (2000). Kesenian Dalam Pendekatan Kebudayaan. Bandung: STSI Press.

Rosmiati, A. (2014). Teknik Stimulasi dalam Pendidikan Karakter Anak Usia Dini melalui Lirik Lagu Dolanan. Jurnal Resital: Journal of Performing Arts, 15(1), 71-82.

Sanjaya, R. M. S. (2013). Metode Lima Langkah Aransemen Musik. Promusika: Jurnal Pengkajian, Penyajian, Dan Penciptaan Musik, 1(1), 34. Retrieved from http://journal.isi.ac.id/index.php/promusika/article/view/538

Setyaningsih, N. R. (2014). Makna Budaya Tembang Tak Lela-lela Ledhung: Sebuah Tinjauan Etnolinguistik. Yogyakarta: Balai Bahasa Daerah Istimewa Yogyakarta, UIN Sunan Kalijaga Yogyakarta, \& BPPKI Yogyakarta.

Spradley, J. P. (2007). The Etnographic Interview. Yogyakarta: PT Tiara Wacana.

Supanggah, R. (2009). Bothekan Karawitan II: Garap. Surakarta: ISI Press Surakarta.

Winarti, D. (2010). Lirik Lagu Dolanan Sebagai Salah Satu Bentuk Komunikasi Berbahasa Jawa: Analisis Fungsi. Widyaparwa, 38(1), 1-12.

Yulianto, S., \& Hananto, P. D. (2009). Laras Pelog Sebagai Dasar Komposisi Empat Bagatelles untuk Ansambel Gitar. Jurnal Musik Universitas Kristen Satya Wacana Fakultas Seni Pertunjukan, 1(1), 17-27. Retrieved from https://repository.uksw.edu/handle/123456789/452 